\title{
Correction to: Extractives of Quercus crispula sapwood infected by the pathogenic fungi Raffaelea quercivora I: comparison of sapwood extractives from noninfected and infected samples
}

\author{
Kayoko Imai ${ }^{1} \cdot$ Tohru Mitsunaga $^{1} \cdot$ Hiroyuki Takemoto $^{2} \cdot$ Toshihiro Yamada $^{3} \cdot$ Shin-ichiro Ito $^{4} \cdot$ Hideo Ohashi $^{1}$
}

Published online: 27 April 2018

(c) The Author(s) 2018

Correction to: J Wood Sci (2009) 55:126-132 https://doi.org/10.1007/s10086-008-1005-1

The article, Extractives of Quercus crispula sapwood infected by the pathogenic fungi Raffaelea quercivora I: comparison of sapwood extractives from noninfected and infected samples, written by Kayoko Imai, Tohru Mitsunaga, Hiroyuki Takemoto, Toshihiro Yamada, Shin-ichiro Ito, Hideo Ohashi, was originally published electronically on the publisher's internet portal (currently SpringerLink) on December 27, 2008 without open access.

With the author(s)' decision to opt for Open Choice the copyright of the article changed on April 27, 2018 to () The Author(s) 2018 and the article is forthwith distributed under the terms of the Creative Commons Attribution 4.0 International License (http://creativecommons.org/licenses/ by/4.0/), which permits use, duplication, adaptation, distribution and reproduction in any medium or format, as long as you give appropriate credit to the original author(s) and the source, provide a link to the Creative Commons license and indicate if changes were made.

The original article has been updated.

The original article can be found online at https://doi.org/10.1007/ s10086-008-1005-1.

Tohru Mitsunaga

mitunaga@gifu-u.ac.jp

1 Department of Applied Life Science, Faculty of Applied Biological Sciences, Gifu University, 1-1 Yanagido, Gifu 510-1193, Japan

2 Center for Ecological Research, Kyoto University, Otsu, Shiga 520-2113, Japan

3 Experimental Section at Chiba, The University Forest, The University of Tokyo, Kamogawa, Chiba 299-5503, Japan

4 Department of Sustainable Resource Sciences, Faculty of Bioresources, Mie University, Tsu, Mie 514-8507, Japan
Open Access This article is distributed under the terms of the Creative Commons Attribution 4.0 International License (http://creativeco mmons.org/licenses/by/4.0/), which permits unrestricted use, distribution, and reproduction in any medium, provided you give appropriate credit to the original author(s) and the source, provide a link to the Creative Commons license, and indicate if changes were made. 